Yalçın, G. ve Altunay, B. (2021). Total düzeyde görme yetersizliği olan öğrencilerin bilgi veren metinlerde dinlediğini anlama düzeylerinin belirlenmesi. Ana Dili Eğitimi Dergisi, 9(3), 771-786.

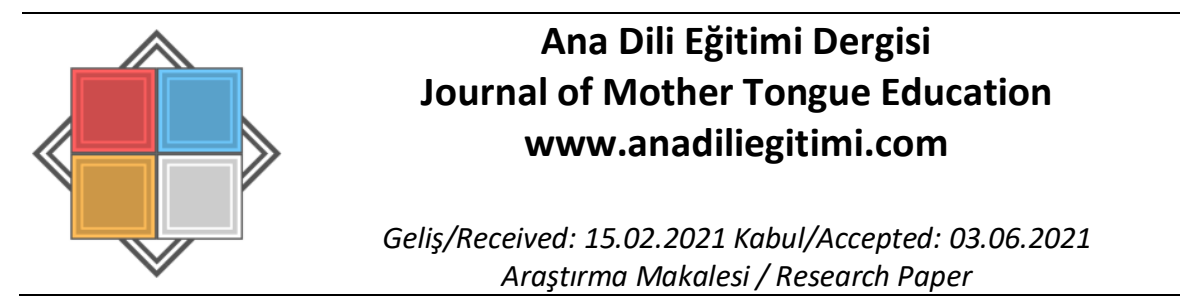

\title{
Total Düzeyde Görme Yetersizliği Olan Öğrencilerin Bilgi Veren Metinlerde Dinlediğini Anlama Düzeylerinin Belirlenmesi *
}

\author{
Gülistan YALÇIN** \\ BanU ALTUNAY***
}

\begin{abstract}
Öz
Bu araştırmanın amacı, eğitim-öğretim süreçlerinde sıklıkla dinleme becerisini kullanan total düzeyde görme yetersizliği olan (kör) öğrencilerin bilgi veren metinlerde dinlediğini anlama düzeylerini belirlemektir. Araştırma, betimsel tarama modeli olarak tasarlanmıştır. Araştırmanın katılımcıları, amaçsal örnekleme yöntemlerinden ölçüt örnekleme yöntemi kullanılarak belirlenmiştir. Belirlenen ölçütleri karşılayan 35 öğrenci ile çalışma gerçekleştirilmiştir. Verilerin toplanması amacıyla iki bilgi veren metin ve bu metinlerin her birine yönelik 12 açık uçlu soru olmak üzere 24 sorudan oluşan dinlediğini anlama veri toplama aracı geliştirilmiştir. Elde edilen veriler SPSS-22 istatistik paket programı kullanılarak analiz edilmiştir. Araştırma sonucunda, total düzeyde görme yetersizliği olan öğrencilerin, bilgi veren metinlerden aldıkları dinlediğini anlama puanların ortalamasının 116,83 olduğu, katılımcıların puanları tek tek incelendiğinde en düşük puanın 63 , en yüksek puanın 195 olduğu görülmektedir. Bu bulgu, testten alınabilecek en yüksek puanın 240 olduğu göz önünde bulundurulduğunda öğrencilerin bilgi veren metinlerde dinlediğini anlama performanslarının düşük olduğu şeklinde yorumlanabilir. Ayrıca araştırmada, öğrencilerin dinlediğini anlama düzeylerinin cinsiyete ve sınıf düzeyine göre farklılık göstermediği sonucuna ulaşılımıştır.
\end{abstract}

Anahtar Kelimeler: Total düzeyde görme yetersizliği, dinlediğini anlama, bilgi veren metin.

\section{Determining Listening Comprehension Levels of Blind Students in Informational Texts Abstract}

The aim of this study is to determine the listening comprehension levels of blind students, who frequently use listening skills in their educational activities and in informational texts. The study was designed as descriptive survey model. Participants of this study were selected with criterion sampling as one of the purposeful sampling methods. The study was carried out with 35 students meeting the specified criteria. As data collection tools, two informational texts and 24 open-ended questions for each of these texts were developed to collect data. The collected data were analysed with SPSS-22 statistics package programme of. As a result of the study, it was seen that the average listening comprehension score of blind students in informational texts is 116,83 . When the participants' scores were examined one by one, the lowest score was found 63 and the highest score was found 195. This finding can be interpreted that the listening comprehension performance of the students in informational texts was low, considering the highest score that can

\footnotetext{
*Bu makale, birinci yazarın Gazi Üniversitesinde tamamladığı doktora tezinden üretilmiştir.

**Dr., Aksaray Üniversitesi, Eğitim Fakültesi, Özel Eğitim Bölümü, Aksaray, gulistanyalcin@aksaray.edu.tr ORCID: orcid.org/0000-0002-9668-0359.

*** Doç. Dr., Gazi Üniversitesi, Eğitim Fakültesi, Özel Eğitim Bölümü, Ankara, abanu@gazi.edu.tr ORCID: orcid.org/0000-0002-1202-1031.
} 
be obtained from the test is 240 . Additionally, it was concluded that listening comprehension levels of students did not vary across gender and grade level.

Key words: Blind, listening comprehension, informational text.

\section{Giriş}

Bilgi ve bilgiye erişim, günümüzün bilgi çağında her zaman kritik konular arasında yer almıştır (Babalola \& Yacob, 2011; Altunay, 2012). Bilgiye erişim, akademik yaşamda son derece önemli bir rol oynamaktadır. Okul ve iş yaşamındaki akademik başarıların, bireylerin önemli bilgileri toplaması ve kullanmasından büyük ölçüde etkilendiği vurgulanmaktadır (Tuncer, 2004). Dünyadaki hemen hemen her ülkede, yetersizliği olan bireylerin de en yüksek oranda kitap okuma olanağına kavuşmaları için yoğun bir çaba sarf edildiği bilinmektedir (Bakırcı, 2009), ancak gelişmekte olan ülkeler, yetersizliği olan bireylerin bilgi ihtiyacını karşılamada sınırlı bir kapasiteye sahiptir. Ülkemizde bireylerin yetersizlikten etkilenmeleri, bilgiye erişimle ilgili problemleri de beraberinde getirmektedir. Görme yetersizliği olan bireyler, bilgiye erişimde dezavantajı gruplar arasında görülmektedir (Babalola \& Yacob, 2011). Görme yetersizliği olan bireylerin alternatif formatta hazırlanmış materyallere ya da düzenlemelere gereksinimi bulunmaktadır. Özellikle görme yetersizliği altında ele alınan, total düzeyde görme yetersizliğinin eğitsel tanımları alternatif formatta hazırlanmıs materyalleri ve gereksinimleri vurgulayacak şekilde yapılmaktadır. Eğitsel tanıma göre total düzeyde görme yetersizliği, öğrenmede dokunsal ve işitsel yolları kullanmaya intiyaç duyan bireyleri ifade etmektedir. Bu bireyler, Braille alfabesi ile basılmış materyalleri okuyarak ve sesli kitapları dinleyerek (Altunay Arslantekin, 2018; Huebner, 2000; Şafak, 2013; Tuncer, 2013), dokunsal formatta hazırlanmış materyalleri (Yalçın \& Kamalı Arslantaş, 2020) ve yardımcı teknolojik araç-gereçleri (Aslan, 2016) kullanarak eğitim öğretimlerini sürdürmektedirler.

Ülkemizde Özbay, Özmen, Tuncer ve Altunay (2007) tarafından yapılan bir araştırmada, görme yetersizliği olan öğrencilerin materyal kullanımında gören akranlarıyla eşit fırsata sahip olmadıkları görülmektedir. Görme yetersizliği olan öğrencilerin farklı bilgi formlarına erişimleri sınırlıdır. ilerleyen yıllarda bu materyallere olan gereksinimler daha da artmaktadır. Öğrencilerin birçok görevi yerine getirebilmesi (sınav, ödev vb.) için farklı formlarda hazırlanmış materyallere ulaşmaları gerekmektedir. Ülkemizde görme yetersizliği olan bireylerin eğitimi için önemli olan dokunsal formatta hazırlanmış materyallere erişimlerindeki (Braille basımın pahalı olması, çok yer kaplaması gibi) problemler nedeniyle görme yetersizliği olan bireylerin, akademik yaşantılarında gören akranlarından farklı olarak dinleme becerisini daha yoğun şekilde kullanmaları gerekmektedir. Özellikle son yıllarda teknolojik cihazlar ve programların neredeyse tamamının sese dayalı olarak geliştirilmesi total düzeyde görme yetersizliği olan öğrencilerin dinleme becerilerini sınıfta ve günlük yaşamda daha sık tercih etmelerine neden olmuştur. Bununla birlikte okullarda eğitim veren öğretmenlerin büyük çoğunluğunun Braille okuma yazma becerilerine sahip olmamaları ve sesli kitap gibi uygulamaların artması (Adetoro, 2012) da total düzeyde görme yetersizliği olan öğrencilerin bilgiye erişimde dinleme becerilerini tercih etmenlerinin nedenleri arasında yer almaktadır.

Görme yetersizliği olan öğrencilerin eğitimindeki başarılarında ve ilerleyen akademik yaşantılarında dinleme ve dinlediğini anlama becerisi son derece önemlidir. Görme yetersizliği olan öğrencilerin akademik yaşamlarında bilgiye erişim için yoğun şekilde kullanmak zorunda olduğu dinleme becerisi, alan yazında pek çok araştırmacı tarafından tanımlanmıştır. Rubin (1995) dinlemeyi, bir dinleyicinin neler olup bittiğini ve konuşmacının neyi ifade etmeye çalıştığını anlamak için işitsel ve görsel ipuçlarından gelen bilgileri seçip yorumladığı aktif bir süreç olarak tanımlamıştır. Buck (2001), dinlemenin kişisel ve bireysel olduğunu ve gelen sesleri deşifre ederek başlayan ve daha sonra bunlardan anlam çıkarılan bir süreç olduğunu ifade etmiştir. Temur (2001) dinlemeyi, dinleyenin önce söylenenlerle sonra söylenenler arasında bağlantı kurup iletişim içerisindeki işlevini anlama yeteneği şeklinde tanımlamıştır. Güneş'e (2013) göre dinleme "Ses, müzik, gürültü, konuşma gibi sesli uyarıııları işitmek, anlamak ve zihinde yapılandırmak için kulak ve beynimizde yürütülen karmaşık bir süreç"tir. Doğan'a (2013) göre dinleme, duyulan sesleri seçme hareketi ve seçiciliğinin söz konusu olduğu, birden fazla ses içerisinden istenilenin seçildiği bilinçli bir faaliyettir. Dinlediğini anlama ise alan yazında ilk kez Rankin tarafından 1926 yılında, "konuşulan dili anlama yeteneği" olarak tanımlanmıştır (Akt. Wolvin \& 
Coakley, 1996). Görme yetersizliği olan öğrencilerin tanımlarda geçen dinleme ve dinlediğini anlama becerilerini öğrenmelerinin akademik yaşamlarındaki önemi nedeniyle, dinleme materyallerini nasıl kullandıklarına yönelik yapılan çalışmalar kilit noktasıdır.

Alan yazında sınırı sayıda yapılan çalışmada, total düzeyde görme yetersizliği olan öğrencilerin, dinleme materyallerini ya da öğretmenlerinin ders anlatımlarını dinlerken pasif dinleyici davranışları gösterdikleri vurgulanmaktadır (Nolan \& Morris, 1969). Öte yandan alan uzmanları, total düzeyde görme yetersizliği olan öğrencilerin, dinleme becerisini nasıl daha etkili kullanacağı ve dinledikleri materyalleri anlamaları için neler yapmaları gerektiği konusunda sınırlı bilgiye sahip olduklarını ifade etmektedirler (Tuncer \& Altunay, 2006; Yalçın \& Altunay Arslantekin, 2019). Görme yetersizliği olan öğrencilerin yaşadığı bu sınırlıı̆̆ın okullarda dinleme becerilerinin öğretiminin yapılmıyor olmasından kaynaklandığı düşünülmektedir. Örneğin Türkiye'de görme engelliler okul programları incelediğinde, öğrencilerin dinleme materyallerini etkili biçimde kullanmalarını sağlamaya yönelik hedeflerin bulunmadığı ve bunun yerine öğrencilerin bilgi veren materyalleri dokunsal olarak işlemeleri boyutuna ağırlık verildiği bilinmektedir. Öte yandan dinleme ve dinlediğini anlama becerisinin, görme yetersizliği olan öğrencilerde kendiliğinden geliştiğine dair yaygın bir inanış da bulunmaktadır (Barraga \& Erin, 1992). Bu inanış total düzeyde görme yetersizliği olan öğrencilerin etkili dinleme becerilerine sahip olmaları için stratejiler geliştirilmesini engellemektedir. Tüm bu durumlar total düzeyde görme yetersizliği olan öğrencilere dinlediğini anlama becerilerinin öğretiminin ihmal edilmesine neden olmuştur. Oysaki öğrencilerin dinledikleri materyalleri anlayabilmeleri için aktif dinleme davranışlarını sergilemeleri beklenir (Tuncer \& Altunay, 2006).

Görme yetersizliği olan öğrencilerin aktif dinleme davranışlarını öğrenebilmeleri için, pek çok ülkede özel olarak tasarlanmış müfredat programları içerisinde doğrudan öğretimlere yer verildiği görülmektedir. Örneğin, Amerika Birleşik Devletleri'nde görme yetersizliği olan öğrencilere genel eğitim müfredatı ile birlikte okutulan Genişletilmiş Çekirdek Müfredat (Expanded Core Curriculum) programının alanlarından biri olan tamamlayıcı akademik beceriler içerisinde dinleme ve dinlediğini anlama ile ilgili amaçlar bulunmaktadır (Yalçın \& Altunay-Arslantekin, 2019). Tamamlayıcı akademik beceriler içerisinde yer alan dinleme ve dinlediğini anlama becerisi; sesin yönünü belirleme, sözlü yönergelere cevap verme, dinleme materyali ile seslendirilen bilgileri takip etme ve anlamlandırma, gürültülü ortamlarda hedef sesi dinleme, ders materyallerini uygun araç gereçlerle dinleme ve dinlediklerini anlama, sözlü sorulara cevap verme gibi pek çok beceriyi kapsamaktadır (Harley, Truan \& Sanford, 1997; Yalçın \& Altunay-Arslantekin, 2019).

Öğrencilere dinleme ve dinlediğini anlamaya yönelik yapılacak sistemli öğretim etkinliklerinin yanı sıra alan yazında öğrencilerin aktif dinleme davranışlarını sergilemesinde bazı faktörlerin etkili olduğu da savunulmaktadır. Genel anlamda bu faktörler; öğrenci ve materyal özelliklerine göre farklııklar göstermektedir (Nolan \& Morris, 1969). Görme yetersizliği olan öğrenciler açısından spesifik olarak ele alındığında, öğrencinin problem davranışının olup olmaması, motivasyonu, dinleme stratejilerini kullanma durumu gibi etmenlerden bahsedilebilir. Materyal özellikleri açısından bakıldığında ise iki farklı boyutta düşünülebilir. Bunlardan ilki materyali dinlemek için kullanılan destekleyici teknolojik programların özellikleri, diğeri ise dinleme materyalinin özellikleridir. Öğrencilerin materyalleri dinlerken hangi programı kullanacaklarıın, hangi ses hızında materyalleri dinleyeceklerinin belirlenmesi kullanılan materyal ile ilgili özelliklerdir. Bu bağlamda öne çıkan konu ise destekleyici teknolojik programlardan biri olan ekran okuma programlarıdır.

Ekran okuma programları, bilgisayar ekranındaki yazılı belge/metin/dokümanları sesli konuşmaya dönüştüren yazılım programlarıdır (Mulloy, Gevarter, Hopkins, Sutherland \& Ramdoss, 2014). Bu programlar bilgisayar, tablet veya akıllı telefonların ekranındaki bilgileri sese dönüştürmekte ve geliştirilen klavye komutları ile görme yetersizliği olan bireylerin ilgili cihazları erişilebilir şekilde kullanmalarını sağlamaktadır. Bu program, görme yetersizliği olan bireylere, konuşma hızını kendi istedikleri gibi ayarlama, farklı tuş kombinasyonlarını kullanarak ekranda yer alan bilgileri harf harf, cümle cümle şeklinde seslendirme imkanı sunmaktadır. Ekran okuma programları, görme yetersizliği olan bireylerin elektronik ortamdaki haber sitesine, basılı kaynaklara ulaşmasında ve pek çok günlük yaşam becerisini bağımsız bir şekilde (örn., internet bankacıllı̆ı) gerçekleştirmelerinde önemli bir kolaylaştırıcı görevi görmektedir. Görme yetersizliği olan bireylerin tercih ettiği ekran okuma 
programları; JAWS, NVDA, VoiceOver, Google TalkBack'dir. Görme yetersizliği olan bireylerin en sık tercih ettiği ekran okuma programlarından olan JAWS (Job Access With Speech) Programı, Windows işletim sisteminin yüklü olduğu bilgisayarlarda çalışan ücretli bir ekran okuma programıdır.

Dinleme materyali açısından bakıldığında ise metin türlerinin öne çıktığı görülmektedir. Total düzeyde görme yetersizliği olan öğrencilerin seçtikleri ya da öğretmenlerinin dinlemeleri için verdikleri metin türüne uygun dinleme davranışları sergilemeleri beklenir (Nolan \& Morris, 1969). Alan yazında hikâye türü ve bilgi veren metin türü olmak üzere iki metin türünden bahsedilir. Hikaye türü metinler, başlangıç ile sonuç arasında dikkatlere sunulan metinler olarak tanımlanmaktadır (Aktaş, 2000). Hikaye türü metinler; destanlar, gezi yazıları, günlükler, farklı türde oyunlar, denemeler, fabllar, mitolojiler, masallar, biyografiler, otobiyografiler ve gezi yazılarıdır (Güzel-Özmen, 2001). Bilgi veren metinler ise belirlenen bir konuda bilgi vermek amacıyla oluşturulmuş metinler olarak tanımlamıştır (Güzel-Özmen, 2011). Bilgi veren metinler, özellikle Fen Bilimleri, Sosyal Bilgiler ve Hayat Bilgisi kitaplarında yer alan metinler, eleştiri yazıları, makaleler, gazete ve dergilerde yer alan haberler, mektuplar, köşe yazıları ve röportajlardır (Güzel-Özmen, 2011).

Alan yazında olağan gelişim gösteren öğrencilerin dinlediğini anlama performanslarını belirlemeye yönelik sınırı sayıda çalışmanın gerçekleştirildiği görülmektedir. Örneğin; Lehto ve Anttila (2003) çalışmalarında 2, 4 ve 6. sınıfa devam eden 107 öğrencinin dinlediğini anlama ve okuduğunu anlama düzeylerini belirlemeyi amaçlamışlardır. Hikâye türü ve bilgi veren metin türü olarak iki farklı boyutta ele alınan çalışmanın bulguları, öğrencilerin bilgi veren metinlerde dinlediğini anlama düzeyinin hikâye türü metinlere göre düşük olduğunu göstermektedir. Yıldııım, Yıldız, Ateş ve Rasinski (2010) ise 5. sınıf öğrencilerinin metin türlerine göre dinlediğini ve okuduğunu anlama düzeylerini belirlemeyi hedefledikleri çalışmalarında 180 öğrenciden veri toplamışlardır. Çalışma sonuçları, öğrencilerin dinledikleri bilgi veren metinlere ilişkin anlama performanslarının düşük olduğunu göstermektedir.

Alan yazında, hem günlük yaşamda hem de akademik yaşamda birincil duyu olarak dinleme becerisini kullanan total düzeyde görme yetersizliği olan öğrencilerin bilgi veren metinlerde dinlediğini anlama performanslarını ortaya koymayı amaçlayan bir çalışmanın bulunmadığı dikkat çekmektedir. Total düzeyde görme yetersizliği olan öğrencilerin eğitim-öğretimde sıklıkla sesli kitapları kullandıkları, Braille formatta erişim sağlayamadıkları kitapları ekran okuma programı aracılığıyla dinledikleri göz önünde bulundurulduğunda dinlediklerini anlama düzeylerinin ortaya konulmasının önemli olduğu düşünülmektedir. Öte yandan yapılan araştırmanın total düzeyde görme yetersizliği olan öğrenci ile çalışan öğretmenlere ve ebeveynlere önemli bilgiler sağlayacağı beklenmektedir.

Bu çalışmada eğitim-öğretim faaliyetlerinde sıklıkla dinleme becerisini kullanan total düzeyde görme yetersizliği olan öğrencilerin bilgi veren metinlerde dinlediğini anlama düzeylerini belirlemek amaçlanmıştır. Bu amaç doğrultusunda aşağıdaki sorulara yanıt aranmıştır.

1. Total düzeyde görme yetersizliği olan ortaokul öğrencilerinin bilgi veren metinlerde dinlediğini anlama düzeyleri nedir?

2. Total düzeyde görme yetersizliği olan ortaokul öğrencilerinin dinlediğini anlama düzeyleri sınıf seviyesine göre farklılık göstermekte midir?

3. Total düzeyde görme yetersizliği olan ortaokul öğrencilerin dinlediğini anlama düzeyleri cinsiyete göre farklılık göstermekte midir?

\section{Yöntem}

Araştırmanın bu bölümünde araştırmanın modeline, katılımcılarına, veri toplama araçlarına, verilerin toplanma sürecine, verilerin puanlanmasına ve verilerin analizine yer verilmiştir.

\section{Araştırmanın Modeli}

Bu çalışmada, total düzeyde görme yetersizliği olan öğrencilerin var olan performansını ortaya koymak hedeflendiğinden betimsel tarama modeli kullanılmıştır. Bu model, geçmişte ya da günümüzde var olan bir durumu var olduğu şekliyle betimlemeyi amaçlar (Karasar, 2013). Bu model ile total düzeyde görme yetersizliği olan öğrencilerin bilgi veren metinlerde dinlediğini anlama düzeylerini belirlenmeye çalışılmıştır. 


\section{Katılımcılar}

Bu araştırmanın katılımcı grubunu, ortaokula devam eden total düzeyde görme yetersizliği olan öğrenciler oluşturmaktadır. Araştırmanın katılımcıları, amaçsal örnekleme yöntemlerinden ölçüt örnekleme yöntemi kullanılarak belirlenmiştir. Ölçüt örnekleme yönteminde örneklem için belirlenen ölçütleri karşılayan kişi, olay ya da nesne/durumlar örnekleme alınırlar (Büyüköztürk, Kılıç Çakmak, Akgün, Karadeniz \& Demirel, 2014). Bu bağlamda katılımcıların belirlenmesinde ölçütler belirlenmiştir. Bu araştırmada katılımcıların belirlenmesindeki ölçütler: (a) Okuma yazma materyali olarak Braille alfabesi kullanması, (b) görme yetersizliği dışında herhangi bir yetersizliği olmaması, (c) JAWS Programı kullanabilmesi ve (d) JAWS Programında metin dinlerken en az $115 \mathrm{hz}$ kullanmasıdır.

Sıralanan ölçütleri karşılayan öğrencilerin belirlenmesinde ilk olarak öğretmen görüşmeleri gerçekleştirilmiştir. Öğretmen görüşmelerinin ardından bir öğrenci listesi hazırlanmış ve öğrencilerle tek tek bir araya gelinerek JAWS Programını kullanma durumları ile ilgili araştırmanın birinci yazarı tarafından değerlendirme yapılmıştır. Yapılan değerlendirme sonucunda belirlenen ölçütleri karşılayan öğrencilerin ailesi ile görüşülmüş, yapılacak çalışma hakkında bilgi verilmiş ve izinleri alınmıştır. Ardından öğrencilerle de bir araya gelinerek çalışma hakkında bilgi verilmiş ve gönüllü olarak araştırmaya katılmak isteyen 35 öğrenci çalışma grubu olarak belirlenmiştir. Aşağıdaki tabloda çalışma grubuna ilişkin özelliklere yer verilmiştir.

Tablo 1.

Çalışma grubu

\begin{tabular}{lllll}
\hline Cinsiyet & $\mathbf{6 . s ı n ı f}$ & $\mathbf{7 . s ı n}$ If & $\mathbf{8 . s i n}$ If & Toplam \\
Kız & 4 & 7 & 3 & 14 \\
Erkek & 7 & 10 & 4 & 21 \\
Toplam & $\mathbf{1 1}$ & $\mathbf{1 7}$ & $\mathbf{7}$ & $\mathbf{3 5}$ \\
\hline
\end{tabular}

Tablo 1 incelendiğinde çalışma grubunun 4'ü 6. Sınıf, 7'si 7. Sınıf, 3'ü 8. Sınıf olmak üzere 14 kız; 7'si 6. Sınıf, 10'u 7. Sınıf ve 4'ü 8. Sınıf olmak üzere 21 erkek öğrenciden oluştuğu görülmektedir. Çalışmaya total düzeyde görme yetersizliği olan toplam 35 öğrenci katılmıştır.

\section{Veri Toplama Araçları}

Total düzeyde görme yetersizliği olan öğrencilerin dinlediğini anlama düzeylerini belirlemek amacıyla 2 bilgi veren metin ve bu metinlere ilişkin hazırlanan toplam 24 açık uçlu sorudan oluşan, Dinlediğini Anlama Veri Toplama Aracı hazırlanmıştır. Aşağıda veri toplama aracının geliştirilme sürecine yer verilmiştir.

Metinlerin Seçimi: Öğrencilerin, daha önce karşılaşmadığı Talim Terbiye Kurulu tarafından onaylanmış Millî Eğitim Bakanlığı tarafından derslerde okutulması önerilen 6 ve 7. sınıf Fen Bilimleri ve Sosyal Bilgiler ders kitapları incelenerek toplam 24 metin belirlenmiştir. Araştırmacılar metinleri tek tek okumuş ve görsel şema ve grafiklere dayanılarak anlatım yapılan metinleri elemişlerdir. Yapılan eleme sonrasında 10 bilgi veren metin kalmıştır.

Metinlerin okunabilirlik düzeylerinin belirlenmesi: 10 bilgi veren metnin okunabilirlik düzeyi Ateşman (1997) tarafından geliştirilen okunabilirlik formülü ile hesaplanmıştır. Aşağıdaki formül kullanılarak 10 metnin, okunabilirlik sayısını bulmak için her metnin ayrı ayrı heceleri, kelimeleri sayılarak hece uzunluğu ve cümle uzunluğu bulunmuştur.

Hece uzunluğu(X1): Toplam Hece Sayısı

Cümle uzunluğu(X2): 100

Toplam Cümle Sayısı

O.S: Okunabilirlik sayısı

Okunabilirlik formülü = O.S:198.825- $(40,175 . X 1-2.610 . X 2)$ 
Metinler için hesaplanan X1 ve X2 değerleri okunabilirlik formülünde yerlerine koyularak metinler için okunabilirlik değerleri hesaplanmıştır. Orta güçlükte çıkan 6 metin uzman görüşü almak üzere Türkçe alan uzmanlarına gönderilmiştir.

Metinlerin uygunluğuna yönelik uzman görüşünün alınması: Uzmanlardan metinleri; kalite bakımından; organizasyonu, kelime seçimi, cümle yapısı, dil bilgisi kuralları, metnin tutarlılı̆ı ve bağdaşıklı̆ı (Graham \& Perrin, 2007) olmak üzere 6 maddeye göre bütüncül olarak (holistic) değerlendirmeleri ve içeriğinin 6,7 ve 8 . sınıf düzeyine uygunluğunun üslup, metindeki fikirler ve kavramsal yoğunluk olmak üzere 3 maddeye göre değerlendirmeleri istenmiştir. Uzmanlar değerlendirmeler sırasında metinleri 1 ila 5 puan arasında puanlamışlardır. Uzmanlardan en yüksek puanı alan 2 metin araştırmada kullanılmıştır.

Anlama sorularının geliştirilmesi: Araştırmada kullanılmak üzere seçilen metinlerin, okunabilirlik düzeylerinin hesaplanması ve uzman görüşlerinin alınmasının ardından araştırmacılar, her bir metni tek tek ayrıntılı olarak okumuş ve metin bilgisine dayanan ve metinden çıkarım yapmaya yönelik açık uçlu sorular hazırlamıştır. Metin bilgisine dayanan sorular, metinde açıkça anlatılmış/sunulmuş bilgi ve düşünceleri bulmaya yönelik olarak oluşturulmuştur. Çıkarımsal sorular ise metinde açıkça anlatılmamış düşünceleri bulmaya yönelik olarak oluşturulan sorulardır.

Araştırmacılar tarafından geliştirilen, her metne ilişkin yirmi anlama sorusu uzman görüşü almak üzere 3 Türkçe Eğitimi alan uzmanına ve bir Ölçme ve Değerlendirme alan uzmanına gönderilmiştir. Uzmanlardan soruları değerlendirirken 1 ila 5 arasında puanlamaları istenmiştir. Uzmanlardan gelen formlar tek tek incelenmiş ve dönütler doğrultusunda düzeltmeler yapılmıştır. Düzeltmelerin ardından sorular tekrar uzmanlara gönderilerek görüşleri alınmış ve son şekli verilmiştir. Araştırmada kullanılan veri toplama aracı; 2 bilgi veren metin ve her metne ilişkin 12 açık uçlu soru olmak üzere toplam 24 sorudan oluşmaktadır.

\section{Verilerin Toplanması}

Aşağıda veri toplama sürecinde izlenen adımlara yer verilmiştir.

Veri Toplama Takviminin Planlanması: Araştırmacılar, öğrencilerin devam ettiği okulların müdür/müdür yardımcıları ile görüşerek öğrencilerden veri toplanacak en uygun zaman aralığını belirlemiştir. Her gün 5 öğrenciden veri toplamak şartıyla veri toplama süreci 7 gün olarak belirlenmiştir. Ancak öğrencilerden ikisinin planlanan günde okulda olmaması nedeniyle veri toplama süreci 8 günde tamamlanmıştır.

Veri Toplama Ortamının Hazırlanması: Araştırmanın verileri, birinci yazar tarafından öğrencilerin eğitim gördükleri okulların rehberlik servisleri için tahsis edilen odada toplanmıştır. Odada bir öğretmen masası ve üç sandalye, bir de kitaplık bulunmaktadır. Araştırmacı öğrenci ile karşılıklı olarak oturacakları şekilde ortamı planlamış ve JAWS Programını açarak 115 ses hızına getirmiştir. Bununla birlikte veri toplama aracını ve ses kayıt cihazını masanın üzerinde hazır bir şekilde bulundurmuştur.

Veri Toplama Süreci: Araştırmacı, veri toplamaya başlayacağı ilk öğrenciyle veri toplayacağı ortama gelmiş, öğrencinin ortamı daha önce tanıyor olması nedeniyle ortamı tanıtmamış yalnızca rehberlik servisinde olduklarını söylemiştir. Ardından araştırmacı ve öğrenci karşılıklı oturmuşlardır. Araştırmacı, '.... size bahsettiğim çalışmayı yapacağı. Önce ilk metni dinleyeceğiz, dinleme işlemi bittikten sonra sana metin ile ilgili sorular soracağım. Bu nedenle metni dikkatli bir şekilde dinle. Hazır mısın?' demiş, öğrenci 'Hazırım' dediğinde ilk metni belirlenen ses hızında JAWS Programını açarak dinletmiştir. İlk metin için dinleme işlemi, 2 dakika 25 saniye sürmüştür. Illk metnin dinleme işleminin tamamlanmasının ardından araştırmacı öğrenciye '... evet metnimizi dinledik. Şimdi dinlediğin metinle ilgili sana sorular soracağım. Soruyu yeniden okumamı istersen bana söyle.' demiş ve 'Hazır mısın?' diye öğrenciye sormuştur. Öğrenci 'Hazırım' dedikten sonra metne ilişkin dinlediğini anlama sorularını öğrenciye tek tek sormuş ve öğrencinin yanıtlarını dijital ses kayıt cihazına ve 'Dinlediğini Anlama Veri Toplama Aracı'na kaydetmiştir. Araştırmacı, 10 dakika ara verdikten sonra, ikinci metni öğrenciye dinletmiştir. İkinci metin 2 dakika 45 saniye sürmüştür. Dinleme işlemi tamamlandıktan sonra o metne ilişkin anlama sorularını öğrenciye tek tek sorarak öğrencinin yanıtlarını ses kayıt cihazına ve veri toplama aracına kaydetmiştir. Tüm öğrencilerle aynı süreç tekrar edilmiştir. 


\section{Verilerin Puanlanması}

Öğrencinin her bir soruya ilişkin doğru yanıtı 10 puan olarak puanlandırılmıştır. Araştırmacı tarafından soru okunmuş, öğrenci; soruya 10 sn. içinde cevap vermezse soru tekrar okunmuş ve cevap vermesi beklenmiştir. Öğrenci yine $10 \mathrm{sn}$. içinde cevap vermez ise diğer soruya geçilmiştir. Öğrenci birkaç cevabı olan soruya tek cevap verip beklerse, 'Başka' diyerek öğrencinin cevaplamaya devam etmesi istenmiştir.

Öğrencilerin soruya metinde yazdığı gibi cevap vermesi ya da kendi cümleleri ile ifade etmesi doğru tepki olarak kabul edilmiş ve 10 puan olarak puanlanmıştır. Öğrencinin sorulara metin ile ilgili ancak soru ile ilgisi olmayan bir cevap vermesi ya da hiç ilgisi olmayan bir cevap vermesi yanlış tepki olarak kabul edilmiş ve 0 olarak puanlanmıştır. Birkaç maddesi olan sorularda birisine, ikisine ya da üçüne cevap vermesi durumunda cevaba göre puanlanmıştır. Örneğin sorunun cevabında 4 madde varsa ve öğrenci iki maddesini söylemiş ise 5 puan almıştır. Öğrencilerin, bir metne ilişkin anlama sorularından alacakları en yüksek puan $120^{\prime}$ dir. Testten alacakları toplam puan ise en fazla 240 'dır.

\section{Verilerin Analizi}

Araştırma kapsamında total düzeyde görme yetersizliği olan öğrencilerin bilgi veren metinlerde dinlediğini anlama düzeylerini belirlemek amaçlanmıştır. Bu temel amaç doğrultusunda araştırmada yer alan 35 katılımcıya iki bilgi veren metin ve bu metinlere ilişkin hazırlanan toplam 24 açık uçlu sorudan oluşan test uygulanmıştır. Elde edilen veriler SPSS-22 istatistik paket programı kullanılarak analiz edilmiştir. Bu amaçla katılımcıların dinlediğini anlama düzeyleri cinsiyet ve sınıf düzeylerine göre karşılaştırılmıştır. İstatistiksel fark analizi yöntemi olarak karşılaştırılacak gruplardaki birey sayısı az olduğu için nonparametrik yöntemler tercih edilmiştir. Cinsiyet bağımsız değişkeni ile ilgili yapılan analizlerde kategori sayısı iki (kız-erkek) olduğu için Mann-Whitney $U$ testi kullanılmışken, sınıf düzeyine göre yapılan karşılaştırmalarda Kruskal-Wallis $\mathrm{H}$ testi kullanılmıştır. Araştırma kapsamında yapılan istatistiksel testlerden elde edilen sonuçların yorumlanmasında 0,05 anlamlılık düzeyi dikkate alınmıştır.

\section{Uygulama Güvenirliği}

Araştırmada veri toplama süreçlerinin, planlandığı gibi uygulanıp uygulanmadığının belirlenebilmesi için uygulama güvenirliği hesaplanmıştır. Uygulama güvenirliği verileri, Gazi Üniversitesi Özel Eğitim Bölümü'nde görev yapan bir uzman tarafından toplanmıştır. Uygulama güvenirliği verisi toplayan uzman, görme engelliler öğretmenliği lisans, görme engellilerin eğitimi yüksek lisans mezunu olup, özel eğitim bölümünde doktora yapmaktadır.

Uygulama güvenirliği verisini toplamak amacıyla uzman, uygulamaların \%40'ını (14 katılımcı) izlemiştir. İşaretlemeler sırasında 'Uygulama Güvenirliği Veri Toplama Aracı'nı kullanmıştır.

Uygulama güvenirliği gözlenen uygulamacı davranışının planlanan uygulamacı davranışına bölünerek yüzdesinin alınması yolu ile hesaplanmıştır (Billingsley, White \& Munson, 1980). Yapılan hesaplamalar sonucunda uygulama güvenirliği \%100 olarak bulunmuştur.

\section{Gözlemciler Arası Güvenirlik}

Araştırmada toplanan verilerin güvenirliğini sağlamak amacıyla Gözlemciler Arası Güvenirlik hesaplamaları yapılmıştır. Katılımcıların Dinlediğini Anlama Test Verilerine dair hesaplamaları yapmak için 'Dinlediğini Anlama Gözlemciler Arası Güvenirlik Formu' kullanılmıştır. Bu form; sorular, soruların cevapları ve gözlemci kaydının yazılacağı Evet-Hayır bölümlerinden oluşmaktadır.

Gözlemciler arası güvenirlik verilerini toplayan gözlemci, Gazi Üniversitesi Zihin Engelliler Öğretmenliği lisans mezunu olup Ankara Üniversitesi Özel Eğitim Bölümü yüksek lisans programını tamamlamıştır. Gözlemci, Gazi Üniversitesi Özel Eğitim Bölümü'nde doktora programına devam etmekte aynı zamanda Aksaray Üniversitesi Özel Eğitim Bölümü'nde araştırma görevlisi olarak çalışmaktadır. İlgili verilerin puanlama kriterleri araştırmacı tarafından gözlemciye eğitim verilerek anlatılmıştır. 
Araştırmada, her sınıf düzeyinden örnekler içerecek şekilde verilerin \%20'si random bir şekilde belirlenerek gözlemciler arası güvenirlik hesaplaması yapılmıştır. Gözlemci, formları doldurduktan sonra, gözlemci ile uyuşan cevapların yüzdesi hesaplanmıştır. Gözlemciler arası güvenirlik verisi, birden fazla gözlemci arasındaki toplam görüş birliğinin, görüş birliği ve görüş ayrılı̆ıını toplamına bölünmesi ve 100 ile çarpılması yoluyla hesaplanmıştır (House, House \& Campbell, 1981). Araştırmada gözlemciler arası güvenirlik \%97 olarak hesaplanmıştır.

\section{Araştırma ve Yayın Etiği}

Bu çalışmada "Yükseköğretim Kurumları Bilimsel Araştırma ve Yayın Etiği Yönergesi" kapsamında uyulması belirtilen tüm kurallara uyulmuştur. Yönergenin ikinci bölümü olan "Bilimsel Araştırma ve Yayın Etiğine Aykırı Eylemler" başlığı altında belirtilen eylemlerden hiçbiri gerçekleştirilmemiştir.

\section{Etik Kurul izni}

Kurul adı = Hakkâri Üniversitesi Etik Komisyonu

Karar tarihi $=04.01 .202101$ Sayılı Toplantı

Belge sayı numarası 01 numaralı karar.

\section{Bulgular}

Total düzeyde görme yetersizliği olan öğrencilerin bilgi veren metinlerde dinlediğini anlama düzeylerini belirlemek amacıyla gerçekleştirilen bu çalışmanın bulgularına yer verilmiştir.

Araştırmada yer alan katılımcıların dinlediğini anlama düzeylerine ait betimsel bulgular Tablo 1'de verilmiştir.

Tablo 1.

Katılımcıların dinlediğini anlama düzeylerine ait betimsel istatistikler

\begin{tabular}{lllll}
\hline $\boldsymbol{N}$ & Min. & Mak. & $\bar{X}$ & SS \\
35 & 63,00 & 195,00 & 116,83 & 40,04 \\
\hline
\end{tabular}

Tablo 1'de görüldüğü üzere, katılımcıların iki metinden aldıkları en düşük puan 63 iken, en yüksek puan 195 ve ortalama puan ise $\bar{X}=116,83$ olarak elde edilmiştir. Elde edilen verilerin kaynağını görebilmek için katıımcıların testlerine ilişkin veri dağılımları aşağıdaki grafikte verilmiştir.

Grafik 1.

Katılımcıların dinlediğini anlama puanlarının dağılımı

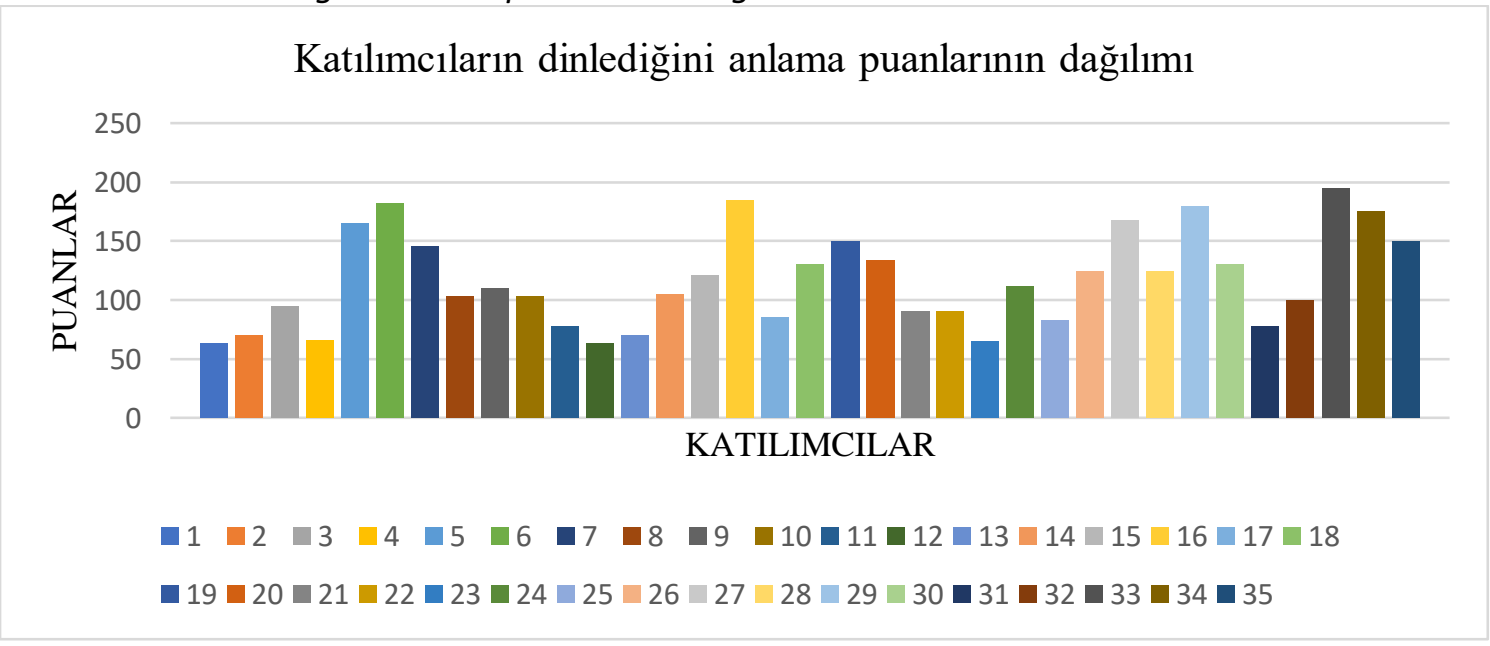


Total Düzeyde Görme Yetersizliği Olan Öğrencilerin Bilgi Veren Metinlerde Dinlediğini Anlama Düzeylerinin Belirlenmesi

Grafik 1'de görüldüğü üzere, dinlediğini anlama testinden 14 katııımcı 0 ile 100 puan arasında puan alırken, 14'ü 101 ile 150 puan arasında, 7'si 151 ile 200 puan arasında puan almıştır. Grafikte, testten alınabilecek olan 240 puanı hiçbir katılımcının elde edemediği görülmektedir. Bununla birlikte testten alınan en düşük puanın 63, en yüksek puanın ise 195 olduğu görülmektedir.

Tablo 2.

Total Düzeyde görme yetersizliği olan öğrencilerin dinlediğini anlama düzeylerinin cinsiyetlerine göre karşılaştırılmasın ait Mann Whitney U-Testi sonuçları

\begin{tabular}{llllll}
\hline Cinsiyet & $N$ & Sira Ortalaması & Sira Toplamı & $U$ & $P$ \\
Erkek & 21 & 16,62 & 349,00 & \multirow{2}{*}{118,00} & \multirow{2}{*}{0,329} \\
$\mathrm{KIz}$ & 14 & 20,07 & 281,00 & & \\
\hline
\end{tabular}

Tablo 2'de görüldüğü üzere, katılımcıların dinlediğini anlama düzeyleri cinsiyete göre istatistiksel olarak anlamlı şekilde farklılaşmamıştır $(U=118,00 ; p>0,05)$. Elde edilen bulgular, araştırma kapsamında yer alan ve total düzeyde görme yetersizliği olan kız ve erkek öğrencilerinin dinlediğini anlama düzeylerinin benzer olduğunu göstermektedir.

Tablo 3.

Total Düzeyde görme yetersizliğiolan öğrencilerin dinlediğini anlama düzeylerinin sınıf düzeylerine göre karşılaştırılmasın ait Kruskal-Wallis H Testi sonuçları

\begin{tabular}{llllll}
\hline Sinıf & $N$ & Sira Ortalaması & Sd & Ki-kare & $P$ \\
6. Sinıf & 11 & 15,32 & & & \\
7. Sinıf & 17 & 17,12 & 2 & 3,58 & 0,167 \\
8. Sinıf & 7 & 24,36 & & & \\
\hline
\end{tabular}

Tablo 3'te görüldüğü üzere, katılımcıların dinlediğini anlama düzeyleri bulundukları sınıf düzeyine göre istatistiksel olarak anlamlı şekilde farklılaşmamıştır $\left(\chi^{2}=3,58 ; p>0,05\right)$. Elde edilen bulgular, araştırma kapsamında yer alan ve total düzeyde görme yetersizliği olan ve farklı sınıflarda (6. 7. ve 8. sınıf) yer alan öğrencilerin dinlediğini anlama düzeylerinin benzer olduğunu göstermektedir.

\section{Tartışma ve Sonuç}

Araştırma sonucunda, total düzeyde görme yetersizliği olan öğrencilerin bilgi veren metinlerdeki dinlediğini anlama puanların ortalamasının 116,83 olduğu görülmektedir. Bununla birlikte katılımcıların puanları tek tek incelendiğinde en düşük puanın 63, en yüksek puanın 195 olduğu görülmektedir. Bu bulgu, testten alınabilecek en yüksek puanın 240 olduğu göz önünde bulundurulduğunda öğrencilerin bilgi veren metinlerde dinlediğini anlama performanslarının düşük olduğu şeklinde yorumlanabilir. Özbay ve diğerleri (2007) tarafından yapılan araştırmada, bir ses kaydını dinledikten sonra sorulan sorulara cevap veren öğrenci sayısının, araştırma grubundaki öğrenci sayısının neredeyse yarısı kadar olduğu belirlenmiştir, fakat araştırmada metin türü açık şekilde ifade edilmemiştir. Bu çalışma araştırma sonuçlarını destekler niteliktedir. Alan yazında total düzeyde görme yetersizliği olan öğrencilerin bilgi veren metinlerde dinlediğini anlama düzeylerini belirlemeyi hedefleyen herhangi bir çalışmaya rastlanılmamakla birlikte, var olan çalışmaların olağan gelişim gösteren (örn., Arslan, 2013; Kodan \& Bozdemir, 2016; Yıldırım vd., 2010), zihinsel yetersizliği olan (örn., Sümer \& Çetin, 2018) öğrencilerle gerçekleştirildiği görülmektedir. Bu çalışmalarda öğrencilerin dinlediğini anlama düzeylerinin, hikâye türü ve bilgi veren metin türüne göre farklılaşıp farklılaşmadığı araştırılmıştır. Çalışmaların sonuçları, öğrencilerin bilgi veren metinlerden hikâye türü metinlere göre daha düşük puanlar aldıklarını göstermiştir. Örneğin, Kodan ve Bozdemir (2016) 4. sınıfa devam eden 103 öğrencinin dinlediğini anlama düzeylerini incelemişlerdir. Çalışmada, öğrencilerin dinledikleri hikâye türü metinleri anlama düzeylerinin, bilgi veren metinleri anlama düzeylerinden daha fazla olduğu sonucu elde edilmiştir. Dolayısıyla çalışmanın bulguları, bu çalışma bulgularını destekler niteliktedir. 
Araştırmada, öğrencilerin dinlediğini anlama düzeylerinin cinsiyete ve sınıf düzeyine göre farklııı göstermediği sonucuna ulaşılmıştır. Bu durum cinsiyet ya da sınıf düzeyi ayırt etmeden total düzeyde görme yetersizliği olan tüm öğrencilerin bilgiyi edinmede birincil duyu olarak dinleme duyularını kullandıklarından kaynaklandığı şeklinde yorumlanabilir. Alan yazında olağan gelişim gösteren öğrencilerle yapılan çalışmalar incelendiğinde ise bu çalışmanın aksine farklı bulgular elde eden çalışmaların da olduğu görülmektedir. Örneğin, Aşılığlu (2009) kız öğrencilerin; Kodan ve Bozdemir (2016) yine kız öğrencilerin dinlediğini anlama performanslarının erkek öğrencilerin performansına göre yüksek olduğu sonucunu elde etmişlerdir.

Öğretmenlerin, görme yetersizliği olan öğrencilere tüm sınıf düzeylerinde dinlediğini anlama becerilerini etkin şekilde kullanmayı öğretmeleri son derece önemlidir (Tuncer \& Altunay, 2006). Görme yetersizliği olan öğrencilere dinleme becerisinin öğretimi, onların ilerleyen akademik yıllardaki başarısını etkileyecektir. Alan yazında yapılan çalışmalar, öğrencilere dinleme becerisi öğretildiğinde öğrencilerin performanslarında artış olduğunu göstermektedir. Örneğin, Yalçın (2020) tarafından yapılan bir çalışmada total düzeyde görme yetersizliği olan öğrencilere dinlediğini anlama performanslarını artırmada Uyarlanmış Çok Ögeli Bilişsel Strateji Öğretiminin etkililiği araştırıımıştır. Çalışma sonucunda total düzeyde görme yetersizliği olan öğrencilerin yapılan öğretim sonrasında bilgi veren metinlerde dinlediğini anlama performanslarında artış olduğu görülmüştür. Benzer şekilde Tuncer ve Altunay (2006) tarafından yapılan çalışmada total düzeyde görme yetersizliği olan öğrencilerin bilgi veren metinlerde dinlediğini anlama performanslarını artırmada özetlemeye dayalı birikimli anlatma stratejisinin etkililiği test edilmiştir. Çalışmada, öğretimler sonrasında öğrencilerin dinlediğini anlama puanlarında artış olduğu görülmüştür.

Total düzeyde görme yetersizliği olan öğrencilerin hem akademik hem de günlük yaşamda en sık tercih ettiği dinleme becerisinin (Yalçın \& Altunay Arslantekin, 2019) erken çocukluk döneminden itibaren öğrencilere kazandırılması gerekmektedir. Ancak hem görme engelliler okul programları hem de genel eğitim programları incelendiğinde dinleme becerileri ile ilgili amaçların oldukça sınırlı olduğu görülmektedir. Özellikle görme engelliler okul programlarında dinleme becerileri ile ilgili amaçların artırılması ve öğrencilere dinleme stratejilerinin öğretilmesi gerekmektedir. Total düzeyde görme yetersizliği olan öğrencilerin, ortaöğretim ve yükseköğretimde daha sık dinleme becerilerinden yararlandıkları bilinmektedir. Bu nedenle özellikle ilköğretim kademesinde bu becerinin edinimi ileriki yaşamlarında öğrenciler için oldukça kolaylaştırıcı olacaktır.

Elde edilen bulgular ışığında aşağıda bazı önerilerde bulunulmuştur:

- Görme yetersizliği; az gören ve total düzeyde görme yetersizliği olmak üzere iki şekilde tanımlanmaktadır. Bu çalışma total düzeyde görme yetersizliği olan öğrencilerle gerçekleştirilmiştir. Benzer çalışma az gören öğrencilerle de gerçekleştirilebilir.

- Bu çalışma 6., 7. ve 8. sınıf öğrencileri ile gerçekleştirilmiştir. Benzer çalışma farklı kademelerde eğitim öğretime devam eden total düzeyde görme yetersizliği olan öğrencilerle de gerçekleştirilebilir.

- Ülkemizde MEB tarafından dağıtılan Braille not alma/okuma cihazı gibi yardımcı teknolojilerle öğrenciye seçim yapacağı ve dinleme becerisini kullanacağı alternatifler sunan uygulamalar yapılabilir.

- Dinleme becerilerinin gelişmesini destekleyecek şekilde total ve az gören bireyler için öğrenme materyalleri/programları geliştirilebilir.

- Özellikle temel eğitim kademesinde görme engelliler okul programında dinleme becerisi ile ilgili daha fazla amaca yer verilebilir.

- Öğretmenler, doğrudan dinleme stratejilerinin öğretimine sınıf ortamlarında yer verebilir.

\section{Araştırma ve Yayın Etiği}

Bu çalışmada "Yükseköğretim Kurumları Bilimsel Araştırma ve Yayın Etiği Yönergesi" kapsamında uyulması belirtilen tüm kurallara uyulmuştur. Yönergenin ikinci bölümü olan "Bilimsel 
Total Düzeyde Görme Yetersizliği Olan Öğrencilerin Bilgi Veren Metinlerde Dinlediğini Anlama Düzeylerinin Belirlenmesi

Araştırma ve Yayın Etiğine Aykırı Eylemler" başlığı altında belirtilen eylemlerden hiçbiri gerçekleştirilmemiştir.

\section{Etik Kurul İzni}

Kurul adı = Hakkâri Üniversitesi Etik Komisyonu

Karar tarihi= 04.01.2021 01 Sayılı Toplantı

Belge sayı numarası 01 Numaralı karar

\section{Yazarların Katkı Oranı}

Araştırmaya birinci yazar \%60, ikinci yazar $\% 40$ oranında katkı sağlamıştır.

\section{Çıkar Çatışması}

Araştırma süresince herhangi bir çıkar çatışması yaşanmamıştır.

\section{Kaynaklar}

Adetoro, N. (2012). Alternative format preferences among secondary school visually impaired students in Nigeria. Journal of Librarianship and Information Science, 44(2), 90-96.

Aktaş, Ş. (2000). Roman sanatı ve roman incelemesine giriş. Ankara: Akçağ.

Altunay Arslantekin, B. (2012). Engel türüne göre materyal uyarlama, hazırlama ve kullanımı. A. Ataman (Ed.). Temel eğitim öğretmenleri için kaynaştırma uygulamaları ve özel eğitim içinde (ss. 141176), Ankara: Vize Yayıncılık.

Altunay Arslantekin, B. (2018). Görme yetersizliği olan öğrenciler, A. Cavkaytar ve D. T. Ersan (Ed.), Özel Eğitim ve Kaynaştırma içinde (ss. 141-179), Ankara: Eğiten Kitap.

Arslan, A. (2013). Çeşitli değişkenler açısından ilköğretim yedinci sınıf öğrencilerinin dinlediğini anlama durumları. Dil ve Edebiyat Eğitimi Dergisi, 2(5), 61-81.

Aslan, C. (2016). Görme engelliler için yardımcı teknolojiler. S. Çakmak (Ed.). Özel eğitim ve yardımcı teknolojiler içinde (ss. 56-92). Ankara: Vize.

Aşılıoğlu, B. (2009). Türkçe öğretmen adaylarına göre derslerde karşılaşılan başlıca dinleme engelleri. Elektronik Sosyal Bilimler Dergisi, 8(29), 45-63.

Ateşman, E. (1997). Türkçede okunabilirliğin ölçülmesi. Ankara Üniversitesi Tömer Dil Dergisi, 58, 171174.

Babalola, Y. T., \& Yacob, H. (2011). Library and information services to the visually impaired-the role of academic libraries. Canadian Social Science, 7(1), 140-147.

Bakırcl, R. (2009). Milli Kütüphane'de görme engellilere sunulan hizmetler ve gelişmeler. Bilgi Dünyası, 10(1), 136-142.

Barraga, N., \& Erin, J. (1992). Visual handicaps and learning (3rd ed). Austin: PRO-ED.

Billingsley, F., White, O. R., \& Munson, R. (1980). Procedural reliability: A rationale and an example. Behavioral Assessment, 2(2), 229-241.

Buck, G. (2001). Asssessing listening. Cambridge: Cambridge University.

Büyüköztürk, Ş., Kılıç Çakmak, E., Akgün, Ö. E., Karadeniz, Ş. ve Demirel, F. (2014). Bilimsel araştırma yöntemleri. (18. Baskı). Ankara: Pegem.

Doğan, Y. (2013). Dinleme eğitimi. Ankara: Pegem Akademi.

Graham, S., \& Perin, D. (2007). Writing text: Effective strategies to improve writing of adolescents in middle and high school. Washington, DC: Alliance for Excellence in Education.

Güneş, F. (2013). Türkçe öğretimi yaklaşımlar ve modeller. Ankara: Pegem A.

Güzel-Özmen, R. (2011). Zihinsel yetersizliği olan öğrencilerin bilgi veren metinlerdeki bilgiler hatırlamalarında şematik düzenleyicilerin iki farklı sunum şeklinin karşılaştırılması. Kuram ve Uygulamada Ĕgitim Bilimleri, 11(2), 785-793.

Harley, R. K., Truan, M. B., \& Sanford, L. D. (1997). Communication skills for visually impaired learners: Braille, print, and listening skills for students who are visually impaired. Springfield-Illinois, USA: Charles $\mathrm{C}$. Thomas Publisher. 
House, A. E., House, B. J., \& Campbell, M. B. (1981). Measures of interobserver agreement: Calculation formulas and distribution effects. Journal of Behavioral Assessment, 3(1), 37-57.

Huebner, K. M. (2000). Visual impairment. In A. Koenig, \& M. Holbrook, (Eds.). In Foundations of education volume I: Instructional strategies for teaching children and youths with visual impairments (pp. 55-76). New York: AFB Press.

Karasar, N. (2013). Bilimsel araştırma yöntemi. (25. Basım). Ankara: Nobel.

Kodan, H., \& Bozdemir, H. (2016). Illköğretim 4. sınıf öğrencilerinin dinlediklerini anlama düzeyinin belirlenmesi. Mehmet Akif Ersoy Üniversitesi Eğitim Fakültesi Dergisi, 1(37), 15-27.

Lehto, J. E., \& Anttila, M. (2003). Listening comprehension in primary level grades two, four and six. Scandinavian Journal of Educational Research, 47(2), 133-143.

Mulloy, A. M., Gevarter, C., Hopkins, M., Sutherland, K. S., \& Ramdoss, S. T. (2014). Assistive technology for students with visual impairments and blindness. In Assistive technologies for people with diverse abilities (pp. 113-156). Springer, New York, NY.

Nolan, C. Y., \& Morris, J. E. (1969). Learning by blind students through active and passive listening. Exceptional Children, 36(3), 173-181.

Özbay, Y., Özmen, E. R., Tuncer T. ve Altunay, B. (2007). Özel eğitimin etkisi ve etkililiği temel araştırması. Ankara: MEB Projeler Koordinasyon Merkezi Başkanlığı.

Rubin, J. (1995). A Guide fort he teaching of second language listening. Şehir: Dominie.

Sümer, S. ve Çetin, M. E. (2018). Zihinsel yetersizliği olan bireylerin dinlediklerini anlama düzeyleri üzerinde geleneksel hikaye okuma ve dijital hikaye kullanımının etkililik ve verimliliklerinin karşılaştırılması. Education Sciences, 13(1), 44-55.

Şafak, P. (2013). Ağır ve çoklu yetersizliği olan çocukların eğitimi. Ankara: Vize.

Temur, T. (2001). Dinleme becerisi. Konu alanı ders kitabı inceleme kılavuzu Türkçe 1-8. Ankara: Nobel.

Tuncer, T. (2004). Görme yetersizliğinden etkilenmiş çocuklar. A. Ataman (Ed.), Özel gereksinimli çocuklar ve özel eğitime giriş içinde (1. Baskı, ss. 293-311). Ankara: Gündüz Eğitim ve Yayıncılık.

Tuncer, A. T. ve Altunay, B. (2006). The effect of a summarization-based cumulative retelling strategy on listening comprehension of college students with visual impairments. Journal of Visual Impairment \& Blindness, 100(6), 353-365.

Tuncer, T. (2013). Görme yetersizliği olan çocuklar. S. Vuran (Ed.), Özel eğitim içinde (ss. 289-321). Ankara: Maya.

Wolvin, A., \& Coakley, C. G. (1996). Listening. Dubuque, IA: Wm. C. C. Brown.

Yalçın, G. ve Altunay Arslantekin, B. (2019). Görme yetersizliği olan öğrenciler için genişletilmiş çekirdek müfredat ve dinleme becerileri. Aksaray Üniversitesi Sosyal Bilimler Enstitüsü Dergisi, 3(2), 298-323.

Yalçın, G. ve Kamalı Arslantaş (2020). Mentoring ınservice teachers to support their inclusive science teaching practices for students with visual Impairment. International Journal of Contemporary Educational Research, 7(2), 112-131.

Yalçın, G. (2020). Uyarlanmış çok ögeli bilişsel strateji öğretiminin görme yetersizliği olan ortaokul ögrrencilerinin dinlediğini anlama ve özetleme becerileri üzerine etkisi. Doktora Tezi, Gazi Üniversitesi Eğitim Bilimleri Enstitüsü, Ankara.

Yıldırım, K., Yildiz, M., Ates, S. ve Rasinski, T. (2010). Fifth-grade turkish elementary school students' listening and reading comprehension levels with regard to text types. Educational Sciences: Theory and Practice, 10(3), 1879-1891.

\section{Extended Abstract}

\section{Introduction}

As compensatory academic skills, listening and listening comprehension include many skills such as, identifying directions of sounds, responding to oral instructions, following directions with audio texts and interpreting, listening the target voice in a noisy environment, listening course materials with appropriate tools, and responding to oral questions (Harley et. al., 1997; Yalçın \& Altunay Arslantekin, 2019). Students with severe visual impairments (blind) prefer listening skills more frequently in their classrooms and daily lives due to many reasons such as the development of 
technological devices and programmes based on sound and inability to access the printed materials. Furthermore, the reason why blind students prefer listening skills in accessing information is that most of the teachers do not have Braille literacy skills and that there is an increase in the applications such as audio books (Adetoro, 2012).

It was stated by the experts that blind students have limited knowledge on how to use listening skills more effectively in their education and what they should do to understand the listening materials (Tuncer \& Altunay, 2006; Yalçın \& Altunay Arslantekin, 2019). It was considered that limitation experienced by the students with visual impairments occurs due to the absence of listening skill courses in the schools. For instance, when curriculum of the school for the visually impaired in Turkey is examined, it is known that there are no goals to enable students to use the listening materials effectively, but the focus is rather on the tactile learning of informational materials.

There is also a common belief that listening and listening comprehension skills are instinctively developed by the students with visual impairments (Barraga \& Erin, 1992). This belief hinders developing strategies for blind students to have effective listening skills. Teaching the listening comprehension skills to the blind students is neglected due to these reasons.

Although there is no study in the literature to determine the listening comprehension levels of the blind students in informational texts, it is seen that there are limited number of studies to determine the listening comprehension performance of normally developing students. Lehto and Antilla (2003) aimed to define listening and listening comprehension skills of 107 students attending the $2^{\text {nd }}, 4^{\text {th }}$, and $6^{\text {th }}$ grades in their education. The findings of the study, including two different dimensions as narrative and informational texts showed that students' listening comprehension level was lower in informational texts than the narrative texts. Yıldııım, Yıldız, Ateş, and Rasinski (2010) collected data from 180 students in their study in which they aimed to determine listening and reading comprehension levels of the $5^{\text {th }}$ grade students according to text types. The results of the study showed that the listening comprehension level of students in informational texts is low.

This study aims at determining the listening comprehension levels of blind students who frequently use listening skills in their educational activities. For this purpose, answers to the following questions are sought:

1. What are the listening comprehension levels of the blind secondary education students in informational texts?

2. Do the listening comprehension levels of the blind secondary education students vary across grade levels?

3. Do the listening comprehension levels of the blind secondary education students vary across gender?

\section{Method}

Descriptive survey model was used in this study which aims to present the listening comprehension levels of secondary education students with severe visual impairments in informational texts. Participants of this study were selected with criterion sampling as one of the purposeful sampling methods. The study was conducted with 35 students meeting the specified criteria.

As data collection tools, 2 informational texts and 24 open-ended questions about these texts were prepared to determine the listening comprehension levels of the blind students. To determine the listening comprehension levels of the participants in informational texts, the first author opened JAWS Programme at sound speed of the laptop in an empty classroom and asked the students to listen to the first text. After the listening process was completed, the researcher asked the listening comprehension questions about the text to the student one by one and recorded the answers on audio recorder and 'Listening Comprehension Data Collection Tool'. Then the researcher ensured the student listen to the second text and when listening process was completed, $s /$ he asked text comprehension questions to the student one by one and recorded the answers on audio recorder and data collection tool. 
The correct answer of the student for each question was scored as 10 points. The researcher read the question and if there was no response in $10 \mathrm{sec} ., \mathrm{s} /$ he read again, and the student was expected to answer. If the student did not answer in $10 \mathrm{sec}$., then the researcher passed on to the other question. If the student responded to a question with multiple answers and waits, the student was asked to continue answering by saying the other.

If the student answered the question as it was written in the text or explained it in his/her own sentences, it was accepted as a correct response and scored as 10 points. If the students' answers to the questions were related to the text, but not to the question, or if their answers were not related to the questions, it was accepted as a false response and scored as 0 . In the cases where the student responded one, two or three items of the multiple-choice questions, it was scored according to the answer. For example, if there were 4 items in the question and the student said two correct items, $\mathrm{s} /$ he got 5 points. The highest score that students can get from comprehension questions related to a text was 120. The maximum score they got in the test was 240 .

The collected data were analysed with SPSS-22 statistics package programme, the listening comprehension levels of the participants were compared according to gender and grade levels. Nonparametric methods were preferred as the number of individuals in the groups to was found low to compare for the statistical discrepancy analysis method. Mann-Whitmey $U$ test was used for gender independent variable since the number of categories was only two (women-men), whereas KruskalWallis $\mathrm{H}$ test was used for the comparisons made by grade level. 0.05 significance level was taken into consideration in interpreting the results obtained from statistical tests conducted within the scope of the study.

\section{Result and Discussion}

As a result of the research, it was seen that the average listening comprehension score of the blind students obtained from the informational texts was found 116.83. However, when the participants' scores were examined individually, it was seen that the lowest score was found 63 and the highest score was found 195. This finding can be interpreted as the listening comprehension performance of the students in informational texts was low, considering the highest score that can be obtained from the test was 240.

Although there is no study in literature that aims to determine the listening comprehension levels of blind students in informational texts, it is seen that existing studies have been conducted with normally developing students (e.g., Arslan, 2013; Kodan \& Bozdemir, 2016; Yıldırım \& et al., 2010), and students with intellectual disabilities (e.g., Sümer \& Çetin, 2018). In these studies, it was investigated whether the listening comprehension levels of the students differ according to narrative texts and informational texts. The results of these studies showed that students get lower scores in the informational texts than the narrative texts. For instance, Kodan and Bozdemir (2016) analysed the listening comprehension levels of 103 students who are attending the $4^{\text {th }}$ grade. As a result of the study, it was found that the listening comprehension level of students in narrative texts was higher than the informational texts. Therefore, their findings align with the findings of this study.

In addition, it was concluded that listening comprehension levels of students do not vary across gender and grade level. This situation can be interpreted as that blind students use auditory senses as primary sense to acquire information regardless of their gender and grade levels. When the studies conducted in literature with normally developing students are examined, it is seen that there are various findings in contrast to this study. For example, Aşlıoğlu (2009) and Kodan and Bozdemir (2016) found that the listening comprehension performance of female students is higher than male students' performance.

\section{Ekler}

\section{Ek-1. Uygulama Güvenirliği Veri Toplama Formu}

Amaç: Bu formun amacı, uygulamacının uygulamış olduğu Dinlediğini Anlama Veri Toplama Aracını hazırlanmış olan uygulama süreçlerine ne ölçüde uygunluk gösterdiğini belirlemektir. 
Total Düzeyde Görme Yetersizliği Olan Öğrencilerin Bilgi Veren Metinlerde Dinlediğini Anlama Düzeylerinin Belirlenmesi

Kullanma Yönergesi: Bu formda, uygulayııının gerçekleştirmesi beklenen, değerlendirme sürecinde bulunan davranışlar yer almaktadır. Formu uygulamadan önce okuyunuz. Değerlendirme süreçlerini izleyerek, uygulamacının bu basamakları yerine getirip getirmediğini belirleyiniz. Bu amaçla, uygulamacı değerlendirme sürecinde yer alan davranışları yerine getiriyorsa "Yaptı" sütununa; yerine getirmiyorsa "Yapmadı" sütununa bir çek atınız. Eklemek istediklerinizi de notlar kısmına yazınız.

Değerlendirme Süreci $\quad$ Yaptı Yapmadı Notlar

1 Veri toplamaya başlamadan önce öğrenciye seninle şimdi bir çalışma yapacağız, diyerek çalışmanın amacını söyler. Daha sonra 'Önce bilgisayarda seçili olan metni dinleyeceksin dinlemen bittikten sonra sana bu metinle ilgili sorular soracağım. Hazır olduğun zaman bana söyle' diyerek yönergeyi verir.

2 Öğrencinin metin dinleme işlemini bitirmesinin ardından öğrenciye metinle ilgili anlama soruları soracağını ve verdiği cevapları kaydedeceğini belirtir.

3 Metne ait kayıt çizelgesindeki, metinde yer alan bilgi birimlerini ve metinden çıkarım yapmaya yönelik olarak olan soruları sırasına uygun olarak öğrenciye sorar.

4 Öğrencinin soruya verdiği cevabı hiçbir şey söylemeden kayıt çizelgesine kayıt eder.

5 Öğrencinin soru sorulduktan sonra tepki vermemesi durumunda 10 sn boyunca cevap vermesini bekler.

6 Öğrencinin sorulan soruya 10 sn içinde tepki vermemesi durumunda soruyu tekrar sorar.

7 Öğrencinin sorulan soruya eksik cevap vermesi durumunda başka, diğer, tekrar düşün gibi şeyler söyleyerek öğrencinin eksik cevabını tamamlamasını 6-7 sn boyunca bekler.

8 Öğrencinin sorulan soruyu 6-7 sn boyunca cevaplamaya devam etmezse öğrencinin ilk olarak söyledikleri tekrar edilerek 'Ben sana, ..... sordum. Sen ..... dedin başka? diyerek öğrencinin cevabına devam etmesinin 6-7 sn bekler.

Gözlemci:

Tarih:

Gözlenen Katılımcı:

\section{Ek-2. Gözlemciler Arası Güvenirlik Veri Toplama Aracı}

Kullanım Yönergesi: Sayın araştırmacı uygulamaya başlamadan önce formda yer alan soruları dikkatlice okuyunuz. Ardından öğrencinin cevabının yer aldığı ses kayıt cihazını dinleyerek öğrencinin cevaplarını not ediniz ve formda evet hayır sütununu kullanarak işaretleyiniz. Her bir soru için puanlamayı araştırmacının size verdiği eğitimdeki bilgilere dayanarak yapınız. Her bir soru için ayrı ayrı puanlama kısımlarına puan veriniz. Son olarak formun altında bulunan Toplam Puan kısmına toplam puanı yazınız.

Öğrencinin adı-soyadı:

Sınıfı:

Uygulama tarihi:

\begin{tabular}{|c|c|c|c|c|c|c|}
\hline No & Soru & Cevap & Evet & Hayır & Açıklama & Puan \\
\hline 1 & $X X X X X X X X X X X X X X X X X X$ & XXXXXXXXXXXXXXXXXXX & & & & \\
\hline 2 & $X X X X X X X X X X X X X X X X X$ & XXXXXXXXXXXXXXXXXXXX & & & & \\
\hline 3 & XXXXXXXXXXXXXXXXXXX & $X X X X X X X X X X X X X X X X X$ & & & & \\
\hline 4 & $X X X X X X X X X X X X X X X X X X$ & XXXXXXXXXXXXXXXXXXX & & & & \\
\hline 5 & XXXXXXXXXXXXXXXXXXX & XXXXXXXXXXXXXXXXXX & & & & \\
\hline
\end{tabular}




\begin{tabular}{|c|c|c|}
\hline 6 & $X X X X X X X X X X X X X X X X X$ & $X X X X X X X X X X X X X X X X X X$ \\
\hline 7 & XXXXXXXXXXXXXXXXXXXX & XXXXXXXXXXXXXXXXXXXX \\
\hline 8 & XXXXXXXXXXXXXXXXXXX & XXXXXXXXXXXXXXXXXXX \\
\hline 9 & XXXXXXXXXXXXXXXXXXX & XXXXXXXXXXXXXXXXXXX \\
\hline 10 & XXXXXXXXXXXXXXXXXXX & XXXXXXXXXXXXXXXXXXX \\
\hline 11 & $X X X X X X X X X X X X X X X X X$ & $X X X X X X X X X X X X X X X X X X$ \\
\hline 12 & XXXXXXXXXXXXXXXXXXXX & XXXXXXXXXXXXXXXXXXXX \\
\hline 13 & XXXXXXXXXXXXXXXXXXX & XXXXXXXXXXXXXXXXXXX \\
\hline 14 & XXXXXXXXXXXXXXXXXXX & XXXXXXXXXXXXXXXXXXX \\
\hline 15 & XXXXXXXXXXXXXXXXXXXX & XXXXXXXXXXXXXXXXXXXX \\
\hline 16 & XXXXXXXXXXXXXXXXXXX & XXXXXXXXXXXXXXXXXXX \\
\hline 17 & XXXXXXXXXXXXXXXXXXX & XXXXXXXXXXXXXXXXXX \\
\hline 18 & XXXXXXXXXXXXXXXXXXX & XXXXXXXXXXXXXXXXXXX \\
\hline 19 & XXXXXXXXXXXXXXXXX & XXXXXXXXXXXXXXXXX \\
\hline 20 & XXXXXXXXXXXXXXXXXXX & XXXXXXXXXXXXXXXXXXX \\
\hline 21 & XXXXXXXXXXXXXXXXXXX & XXXXXXXXXXXXXXXXXXXX \\
\hline 22 & XXXXXXXXXXXXXXXXXXX & XXXXXXXXXXXXXXXXXXX \\
\hline 23 & XXXXXXXXXXXXXXXXXXX & XXXXXXXXXXXXXXXXXXX \\
\hline 24 & XXXXXXXXXXXXXXXXXXX & XXXXXXXXXXXXXXXXXXX \\
\hline
\end{tabular}

Toplam Puan:

\section{Ek-3. Örnek Dinleme Metni}

\section{YENIDEN DOĞUŞ: RÖNESANS}

Orta Çă̆'da, Avrupa'da bilim ve sanatta dinin ve kilisenin egemenliği söz konusuydu. Kilise düşünmeyi imkânsız kılmıştı. Bu dönemde Dünya'nın düz olduğu gibi inanışlar yaygındı. Avrupa'da, Orta Çağ bilimsel gelişme bakımından karanlık bir dönemdi.

Coğrafi Keşiflerde elde edilen bilimsel bilgiler ile kilise ve din adamlarına duyulan güven azaldı. Bu durum karşısında kilise güç kaybetmeye başladı. Kilise baskısının azalması insanların daha özgürce tartışıp düşüncelerini geliştirme olană̆ı bulmasını sağladı. Kâğıdın bol ve ucuza mal edilmesi ve matbaa sayesinde çok sayıda ve ucuz kitabın basılması, yeni bilgi ve düşüncelerin hızla yayılması gibi durumlar gerçekleşti.

Coğrafi Keşifler sonucunda ticaret gelişti. Ticaretle zenginleşen, sanatı seven ve sanatçıları koruyan zengin bir sınıf ortaya çıtı. Bu sınıf Avrupa'da sanatçıları ve bilim insanlarını destekledi. Böylece 16. yüzyılda birçok sanatçı yetişti. Eski Yunan ve Roma uygarlıklarına ait eserlerin incelenmesi ve değerlendirilmesi bilim ve sanat anlayışını geliştirdi. 15 ve 16. yüzyıllarda, Avrupa'da meydana gelen edebiyat, kültür, güzel sanatlar, bilim ve düşünce alanlarındaki bütün bu yenilik ve gelişmelerin yaşandığı döneme yeniden doğuş anlamına gelen Rönesans adı verildi.

Rönesans Döneminin en önemli temsilcilerinden biri Leonardo da Vinsi'dir. Da Vinsi, resim, mimarlık, bilim, felsefe ve mühendislik alanlarında yaptığı çalışmalarla döneme damgasını vurdu. Da Vinsi, insanın anatomik yapısını inceleyerek doğru tasvir etmeyi amaçladı. Leonardo da Vinsi'nin insan anatomisi üzerine yaptığı çalışmalar günümüz biliminin gelişmesine büyük katkı sağladı. Anatomi alanındaki çalışmalarıyla bilim tarihinde bilinen ilk robot tasarımını yaptı. 1495 yılında yaptığı bu tasarım ancak 1950'lerde keşfedildi. Da Vinsi'nin Leonardo'nun robotu adı verilen bu tasarımı, kalp rahatsızlıklarının tedavi edilmesinde, 2005 yılında bir İngiliz kalp cerrahına esin kaynağı oldu.

Rönesans Döneminde, Leonardo da Vinsi'den başka günümüz bilim ve sanatının gelişmesine katkısı olan pek çok sanatçı ve bilim insanı yetişti. Ünlü heykeltıraş Mikelanj, denemeleriyle tanıdığımız Monteyn, dinde reformu başlatan Luter, tiyatro eserleriyle tanınan Şekspir, ilk defa Dünya'nın Güneş etrafında döndüğünü söyleyen Kopernik, Rönesans'ın temsilcileri oldular. 